\title{
"We just have to continue working": Farmworker self-care and heat-related illness
}

\author{
Michael D. Courville ${ }^{a *}$ \\ California Institute for Rural Studies \\ Gail Wadsworth b \\ California Institute for Rural Studies
}

Marc Schenker ${ }^{c}$

University of California, Davis

\begin{abstract}
Submitted August 7, 2015 / Revised October 2, 2015 / Accepted October 21, 2015 /
Published online March 2, 2016

Citation: Courville, M. D., Wadsworth, G., \& Schenker, M. (2016). "We just have to continue working": Farmworker self-care and heat-related illness. Journal of Agriculture, Food Systems, and Community Development, 6(2), 143-164. http://dx.doi.org/10.5304/jafscd.2016.062.014
\end{abstract}

Copyright (C) 2016 by New Leaf Associates, Inc.

\begin{abstract}
Heat-related illness (also called heat illness) is a recurring and avoidable condition that results in multiple deaths in California farm fields every year. We conducted five focus groups as part of the California Heat Illness Prevention Study (CHIPS) in Fresno, California, during the summer of 2013. We used qualitative coding methods to analyze focus group transcript data with consideration of
\end{abstract}

a* Corresponding author: Michael D. Courville, California Institute for Rural Studies; P.O. Box 1047; Davis, California 95617-1047 USA; +1-530-756-6555 x18;

mcourville@,cirsinc.org

b Gail Wadsworth, California Institute for Rural Studies; P.O. Box 1047; Davis, California 95617-1047 USA; +1-530-756-6555 x17; gwadsworth@,cirsinc.org

c Marc Schenker, Department of Public Health Sciences, University of California-Davis School of Medicine, Davis, California 95616 USA; mbschenker@ucdavis.edu workers' behaviors and beliefs, workplace safety training experiences, employer-employee relations, and workplace conditions and organization. Discrete and complex factors related to worker self-care were identified, and suggest that heat illness cannot be viewed as simply a biomedical or behavioral issue, and that preventive health interventions in agriculture also need to take into account power and control structures existing in

\section{Disclosures}

Michael Courville worked with the California Institute for Rural Studies in 2014 through a consultancy (Open Mind Consulting) to conduct some data analysis presented in this paper. He later became a direct employee of CIRS in the spring of 2015, during the manuscript development and submission period.

The University of California-Davis Western Center for Agricultural Worker Health and Safety provided funding for this project through award number $2 \mathrm{U} 54 \mathrm{OH} 007550$ PHS from the U.S. Centers for Disease Control. 
the industry. Findings indicate that prevention plans should be guided by strategies that integrate worker control with work-site organization and employer relations, as opposed to strategies that focus exclusively on traditional modes of training to advance prevention.

\section{Keywords}

California agriculture, safety training, heat illness, heat-related illness, farmworker, qualitative analysis, wage labor, worker control

\section{Introduction and Literature Review}

The major environmental risk factors for heatrelated illness (HRI) ${ }^{1}$ or heat illness are known, as are many personal risk factors. ${ }^{2}$ Regulations have been enacted to help protect workers, yet deaths and significant levels of HRI still occur, particularly among agricultural workers. HRI is an area of agricultural worker health and safety that has not been adequately addressed by the research and outreach community. In the U.S. from 1992 to 2013 (the most recent year of reporting) at least 689 workers have died and 56,114 have been injured severely enough to result in days away from work due to HRI (Centers for Disease Control and Prevention [CDC], 2008; U.S. Department of Labor, Bureau of Labor Statistics, n.d.). Agricultural workers are by far the most severely affected group of workers, with an annual heat-related death rate for crop workers at 0.39 per 100,000 workers, compared with 0.02 for all U.S. civilian workers (CDC, 2008). California has the largest population of farmworkers in the nation, with an estimated range of between 350,000 and 400,000 individuals engaged in field labor. ${ }^{3}$ California's San Joaquin Valley is home to a large proportion of the state's agricultural workers (Villarejo \& Runsten, 1993; Walker, 2004), who work in extremely high

\footnotetext{
1 There are differences between what symptoms and physical conditions constitute heat illness and heat stress. The more general "heat-related illness" is used to refer to a range of symptoms and conditions that can result as an effect of exposure to extreme heat and sun for long periods of time. 2 The environmental factors include exertion in hot weather outdoors; sudden exposure to hot weather; prolonged
}

\section{Figure 1. Map of California with the San Joaquin Valley Outlined and Study County in Red}

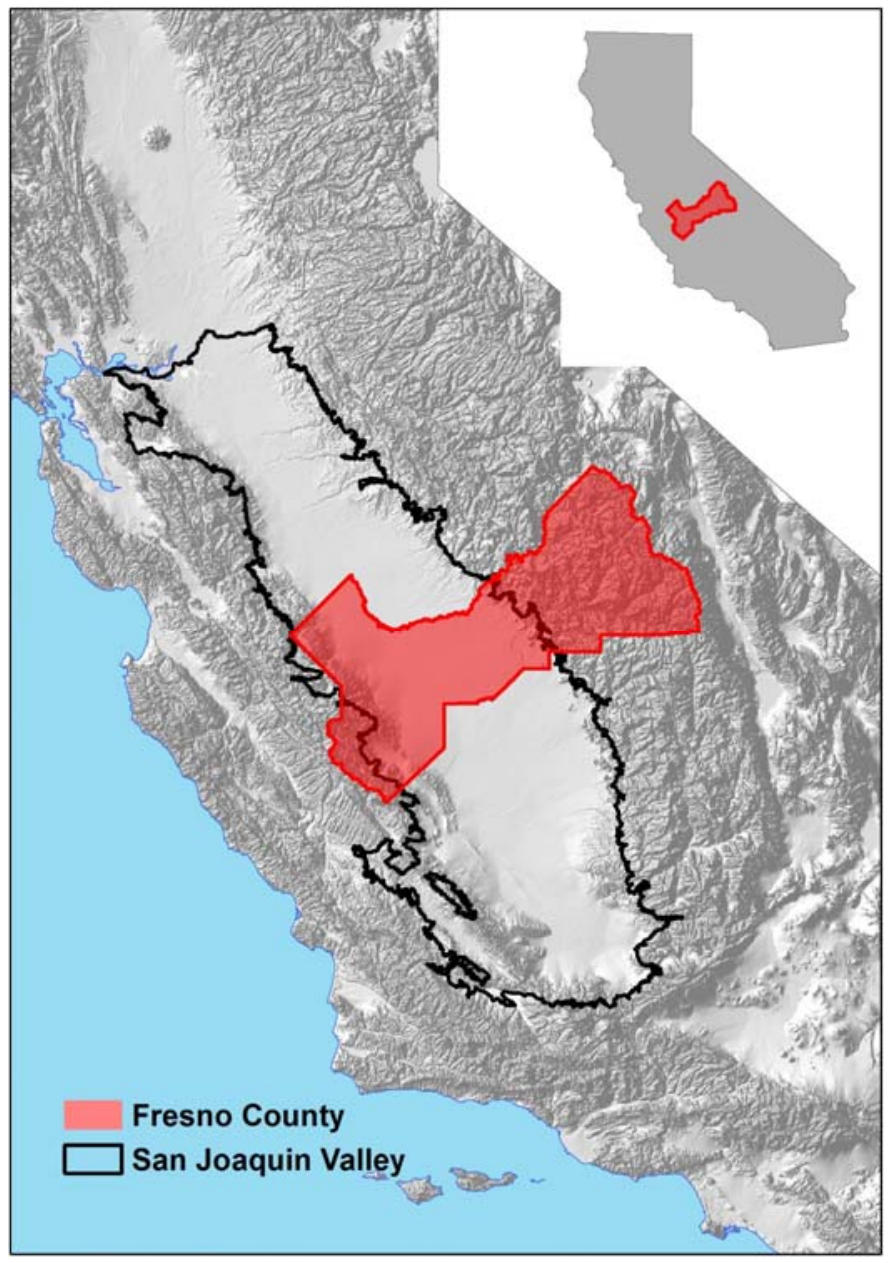

Map created by Patrick Huber.

temperatures (see Figure 1). From 2005 to 2009 the California office of the Occupational Safety and Health Administration (OSHA) received reports of 93 cases of severe HRI among farmworkers, a timespan that included a spate of three deaths during the summer of 2006 (California Department of Industrial Relations, 2007). Additionally, the rate of heat-related fatalities increased over the past decade. It is likely that extreme heat events will

exposure to the sun; and exertion under high temperatures indoors. The personal risk factors include age (i.e., very young or over 65); use of certain medications; and existence of chronic diseases such as heart or lung disease.

3 See Mines, Ward, and Schenker (2000) for a good discussion of the challenges related to farmworker enumeration. 
continue to increase with global climate change (California Department of Public Health, 2008; McCarthy, Canziani, Leary, Dokken, \& White, 2001).

The California Heat Illness Prevention Study (CHIPS) was initiated in 2013 in response to the ongoing impact of heat on farmworkers. The goal of the CHIPS is to understand the physiological responses to environmental heat and physical work among California farmworkers, and the sociocultural influences that affect the workers' behavior, which may increase their risk of suffering from HRI. Ultimately, information gained from the study will lead to improved HRI prevention strategies for both the employers and employees on farms. Understanding the relationship between how a worker identifies a potential workplace health risk, and then takes steps to prevent that risk, are topics of concern and debate within the literature on worker health (Burke et al., 2006; Cohen \& Colligan, 1998; Lam et al., 2013). A study of HRI among North Carolina farmworkers by Mirabelli et al. (2010) identifies specific factors that contribute to effective prevention and avoidance of HRI, but it also raises questions about persistent HRI incidences that occur despite farmworker knowledge of prevention techniques.

California is an excellent case study for understanding the complexity of HRI occurrence and prevention. California currently has the most stringent regulations protecting outside workers from HRI, including specific requirements for shade, water, and training (California Heat Illness Prevention Regulation, 2010). ${ }^{4}$ Yet there are still over 200 heat-related workplace illness claims annually in California, and this number increases significantly during years of severe heat episodes. Considering the national incidences of worker fatalities due to heat stress (CDC, 2008; Rao, 2007; U.S. Department of Labor, OSHA, n.d.-a), it appears that workers exert themselves in the fields beyond healthy limits, even though intervention strategies are in place, including workplace training (Stoecklin-Marois, Hennessy-Burt, Mitchell, \&

\footnotetext{
${ }^{4}$ The 2010 regulations were amended in May 2015, shortly before this paper was submitted for publication. The findings in this paper were analyzed in consideration of the earlier 2010
}

Schenker, 2013; U.S. Department of Labor, OSHA, n.d.-b). This poses questions about the assumptions that undergird current HRI prevention strategies and regulatory practices in California. The current emphasis on training, learning and regulatory protection to address HRI means the locus of change for workplace safety is vested in voluntary worker action and employer compliance (U.S. Department of Labor, OSHA, n.d.-c).

CHIPS provides an opportunity to explore the motivations, actions, and articulated beliefs of farmworkers in relation to HRI, and to better understand how they receive information from their employers and fellow workers to reduce harm at work. Research on worker education related to risk reduction has focused on the importance of training and teaching methods, finding that "training involving behavioral modeling, a substantial amount of practice, and dialogue is generally more effective than other methods of safety, and health training" (Burke, et al., 2006, p. 315). This body of literature on occupational training directs attention to how workers learn, what they do with new information they receive in workplace safety trainings, and how they understand the origin and causes of illness (Burke, et al., 2006; Cohen \& Colligan, 1998). However, looking only at the effects of training on individuals does not help to explain or illuminate the persistence of HRI within the farmworker labor force over time.

Investigations of worker subjectivity and group relationships have found that the reproduction of worker identities and behavioral choices help explain the persistence of compromised worker health and well-being over time. Research has found that subjective views influence and shape the behaviors and choices of workers, as well as their role in the labor force (Duke, 2011; Georgakas \& Surkin, 1999; D. R. Holmes, 1989; S. M. Holmes, 2013). Additionally, membership within particular groups based on race (Duke, 2011; Mines, Nichols, \& Runsten, 2010), ethnicity (Landrine \& Klonoff, 2004), gender (Martin, 2003), and citizenship

regulations, which were still in effect during the period of data collection and analysis. 
(Martin, Fix, \& Taylor, 2006; Thomas, 1985) also shapes both self-care behavior and overall workplace dynamics in unique ways. These findings shed light on the social contexts facing workers, pointing to structural relationships that bound the range of worker agency. Moreover, the everyday contexts and frameworks that workers draw upon to make sense of their world have social and material dimensions within agricultural production and require explanation (Knights, 1990; Mann, 1990; Thomas, 1985).

Social scientists debate the nature of agricultural production (Mann, 1990; McMichael, 1994) and the persistent forms of farm labor in highly industrialized societies like the United States (Majka \& Majka, 1982; Martin, 2009; McWilliams, 1935). Despite significant debates, most social scientists agree that agricultural employment remains at low wages and with fewer worker protections than those found in other sectors (e.g., manufacturing) (Aldrich, 1997; Guthman, 2004; Mendeloff, 1979; Walker, 2004). During negotiations to approve the Fair Labor Standards Act of 1938, President Roosevelt agreed to concessions to Southern Democrats in the legislature in order to improve conditions for the majority of workers in the country (Samuel, 2000). Farmworkers were excluded from this agreement in order to achieve the goal of fair standards for the majority of lowwage American workers. Such concessions are complicated further by the highly stratified relations of production and workplace management found in agriculture (S. M. Holmes, 2013; Lobao, 1990; Wells, 1996). Taken together, the lack of adequate workplace protections and stratified workplace management focus attention on the dimensions of farmworker behavior and relationships within the organization and the structure of the workplace itself.

Thomas (1985) found evidence that employers in agriculture use direct and indirect means of control to increase worker productivity, and that this extends to choices they make related to workplace organization. Relationships between such

${ }^{5}$ Mixteco is an indigenous language spoken by the Mixtec people of Mexico. The number of Mixtec working in California agriculture has grown steadily over types of control in workplace settings have been found to negatively affect worker health (Karasek \& Theorell, 1990; Theorell, 2003). Such control efforts mitigate conflict between workers and employers (Knights, 1990; Knights \& Willmott, 1990; Thomas, 1985) and speed up the pace of work at the expense of worker health (Fairris, 1998; Grzywacz et al., 2014). Westerlund et al. (2010) found that management style also affects the well-being of workers, pointing to further consideration of employer relations as another variable influencing worker self-care.

\section{Applied Research Methods}

The findings we present are from a systematic review of focus group transcripts gathered as one component of a larger study for CHIPS on HRI among farmworkers. Data collection started in the summer of 2012 and will continue through 2016. Purposive sampling was used to identify and recruit focus group participants. Staff from local community-based organizations serving farmworkers in the Fresno area recruited participants through the use of a screening tool that ensured all participants had at least two years of experience as a farmworker in California and were over 18 years of age. Candidates were then chosen to participate if they worked in California fields within the past three years (i.e., between 2011 and 2013) and had experience working outside during daylight in high summer temperatures (i.e., June through September). A team of experienced, multilingual English/ Spanish/Mixteco ${ }^{5}$ moderators facilitated five focus groups between June 13, 2013, and August 9, 2013, with a total of 48 farmworkers.

Two groups were administered exclusively with women, and two were administered exclusively with men. The remaining group was mixed gender. The focus groups were conducted in nonwork settings administered at Fresno-based nonprofits (one that specifically serves indigenous people from Mexico, and another that specifically serves farmworkers). Findings from earlier studies of heat illness among outdoor workers informed

the last two decades. For a good discussion of indigenous Mexican communities and languages, see Mines et al., 2010. 
focus group question development, resulting in three broad categories of inquiry: worksite experiences and behaviors; individual knowledge of HRI symptoms and treatment; and routines both before and after work. We then developed and organized open-ended questions into a moderator guide to explore specific beliefs and behaviors related to hydration, resting in shade, and training around HRI.

All focus groups were recorded on audio equipment. Written transcripts were generated from these recordings, first in Spanish and then translated into English by trained research assistants. The majority of recordings were in Spanish, but for the sessions conducted in Mixteco, recordings were translated into Spanish before finally being translated into English. Five sets of transcripts, prepared as electronic documents, were then reviewed for technical accuracy, general completeness, and overall content. Minor data cleaning was performed on the transcripts to address technical errors and language and/or word choice decisions made by the transcription team.

We used qualitative analytical methods to conduct a content analysis of the transcripts. A process of open coding was undertaken through written note-taking, in conjunction with the literature review presented above. We pursued a variableoriented analysis, given that the design of the focus group emphasized certain variables through the use of a moderator discussion guide. Basic descriptive statistics related to the Fresno focus group cohort (Cohort) were also tabulated, to complement the transcript coding and to further contextualize the initial findings.

The open coding yielded a set of holistic codes that captured high-level themes and recurring ideas for further investigation. The research team then discussed the holistic codes before a second round of axial coding was conducted using electronic code notations in Microsoft Word. A process of analytic memoing and variable mapping then followed the axial coding. A second analyst conducted an additional review of the transcripts using the axial code list in order to assess intercoder reliability. No codes were eliminated or added as a result of the secondary review. Finally, we organized the codes using a series of displays, tables, and concept-mapping techniques to identify patterns, trends, themes, and any clustering of variables within the coded transcripts.

\section{Results and Discussion}

\section{Participant Profile}

Members of the Cohort consisted of individuals who live in the area and work as farm laborers in Fresno County $(N=48)$. Most participants had worked as farm laborers in the United States for more than two years $(n=41)$, bringing many years of experience in the field to bear on the subject of HRI. Most of the participants referred to being residents of Fresno County or the greater San Joaquin Valley (see again Figure 1).

I have been here for eleven years here, and since I arrived I worked in a factory for four years, and for six years I have worked in the field, and right now I'm picking melons. (Participant \#8, Farmworker Focus Group, August 8, 2013)

We arrived here in '99, so we have been working here for about eleven, twelve years. I work in the field, I work on grapes, pruning, defoliation of peaches. I also work in construction. I have been working in California for about twelve years. (Participant \#5, Farmworker Focus Group, June 14, 2013)

Cohort responses reveal their experiences not just as farmworkers, but also as local residents within a larger community network doing similar work in agriculture over long periods of time. Cohort members work on a variety of tasks in the fields. Even though some participants had stints performing farm labor outside of the San Joaquin Valley, they usually return to engage in similar work each year.

I have worked in the field for 15 years. I do all types of work; here [in Fresno] I pick grapes, I do the rollings [of the grape leaves]. I pick up the raisins, cleaning the raisins. When that gets done, I take a break 
and then the pruning season starts, we tie the vineyards. At the end of the pruning season, we take another break and then the leaves start....Then, we also go to Oregon, to pick strawberries, blackberries, and blueberries. We go there a two-months season and then we come back here [to Fresno]. We just came back from there. (Participant \#4, Farmworker Focus Group, August 9, 2013)

While there were no specific questions in the moderator guide to elicit participant ethnicity or race, the moderator asked participants to identify "where they were from," and this can serve as a proxy for ethnicity. ${ }^{6}$ Responses to this question,

Table 1. Select Attributes of the Fresno Cohort $(N=48)$

\begin{tabular}{ll}
\hline Attribute & Number \\
\hline Gender & \\
Male & 30 \\
Female & 18 \\
\hline Language a & \\
Spanish & 25 \\
Mixteco & 23 \\
\hline
\end{tabular}

a Based on the language used in the administration of each focus group.

Table 2. Most Recent Workforce Activity

\begin{tabular}{lc}
\hline Position & Number \\
\hline Field Work/Harvest & 41 \\
\hline Maintenance and Irrigation & 1 \\
\hline Supervisor & 2 \\
\hline Packing and Sorting & 2 \\
\hline Processing/Factory & 1 \\
\hline Trucking/Shipping & 1 \\
\hline
\end{tabular}

${ }^{6}$ The moderators asked a variation of the following prompt at the start of each group: "Tell us your name, where you are from - what village or state you are from if you are from Mexico, or if you were born here, your city.”

${ }^{7}$ Some participants identified the Mexican state or village where they lived before coming to the United States to work in agriculture. While this level of information about origin has value to understanding some of the pathways and, perhaps, combined with the languages of focus group administration, indicated that the Cohort was 96\% Mexican (one did not answer and one stated he was from Texas), with about half of the participants identifying as indigenous peoples from $\mathrm{Mexico}^{7}$ (see Table 1). The majority of the participants described their experiences as hired farmworkers on a seasonal basis within particular crops or crop harvest cycles (see Tables 2 and Table 3). Family experiences were not discussed in great detail, but the data also suggest a regular home life within California for most, if not all, of the participants. Some Cohort members had families working with them in the fields, including young children. Several participants worked outside of California, with the state of Washington as the most frequently mentioned location.

Finally, the structure of payments, or pay schemes, for the participants helps give context to the relationship between Cohort members and their various agricultural employers. Table 4 summarizes the forms of these payment relationships as identified by the participants (some participants identified more than one relationship).

\section{Organization of Findings}

We present findings first on the discrete factors that shape individual behaviors, and then posit a more direct relationship between worker behaviors and HRI: drinking and eating habits; self-care routines and patterns; worker knowledge and perceptions of HRI; worker training and education; and learning and worker beliefs. Analysis of the more discete factors yielded a complex model of factor clusters, which then served as a dynamic conceptual tool for interpreting our findings on individual worker behaviors and HRI. A noted divergence among workers with regard to genderbased perceptions is also explored within this section of the paper. Following the discussion of

cultural variability between workers, the qualitative nature of this analysis makes these references less reliable as indicators. For this reason, a higher level of categorization was used to avoid speculation about the participants' specific regional or community affiliation. For a good discussion of regional and village-level factors related to farmworker experiences in California, see Mines et al. (2010). 
Table 3. Participant Crop and Harvest Experience

\begin{tabular}{lll}
\hline Identified Crops & & \\
\hline Fruit & Vegetables & Tree Nuts, Grains and Fibers \\
Apples $\checkmark$ & Broccoli & Almonds \\
Blueberries $\checkmark$ & Garlic & Alfalfa \\
Blackberries $\checkmark$ & Tomatoes & Cotton \\
Cherries & & Other grains, not specified $\checkmark$ \\
Grapes & \\
Melons & \\
Mandarins/Oranges & \\
Peaches & \\
Plums & \\
Raisins & \\
Strawberries & \\
\hline
\end{tabular}

Note: A checkmark $(\boldsymbol{V})$ denotes indication by participants that these crops were harvested outside of California.

the discrete factors, we then present findings related to overarching structural patterns and trends that help explain shared experiences across the larger Cohort.

\section{Drinking and Eating Habits}

One of three tenets in the current OSHA campaign to prevent heat stress is a reminder for workers to drink water, in conjunction with periods of rest and the use of shaded areas (U.S. Department of Labor, OSHA, n.d.-c). Hydration during prolonged periods of sun exposure and high temperatures is an accepted practice for reducing and avoiding HRI. This guidance is based on the assumption that by encouraging workers to drink more water during the workday, incidences of HRI will be reduced.

Transcript data were coded for patterns related to water consumption, and individual beliefs about the effects of drinking water throughout the workday. Cohort members generally understood the benefits of drinking water while working in the heat; however, there was a great deal of variability in actual hydration practices. This variability and the range of beliefs about the properties and impact of water on the body present a more complicated view of daily Cohort behavior. It was not possible to gauge the frequency of water consumption in the field, ${ }^{8}$ although it was clear that Cohort members drink a range of beverages before, during, and after work. Water is least associated with a desire to "cool down" or "stay healthy." Instead, the coded data reveal beverage consumption patterns that exacerbate symptoms and actually advance the likelihood of HRI. Table 5 illustrates five primary participant motivations for consuming beverages throughout the workday. The concept of hydration, or the recurring need to consume water for optimal health and body functioning, appears very rarely in Cohort discussions. This is significant

Table 4. Cohort Employment Status and Payment Schemes

\begin{tabular}{ll}
\hline Employment Status, Pay Scheme & Common Cohort Description \\
\hline Contract, Piece Rate & Piece, Piece Rate \\
Specific agreement to produce or deliver a certain number or amount of harvested & \\
produce, by weight or volume (e.g., boxes, buckets) with no obligation to pay for actual time & \\
worked, and no ceiling on how much can be earned unless otherwise stipulated. Under & such an agreement a worker is still entitled to a minimum wage floor. \\
\hline
\end{tabular}

Contract, Hourly Wage Hourly

Governed by state wage and hour rules regarding breaks, meal periods, and payment for time worked, regardless of any productivity measurements.

Salary, Hourly Wage
Regular, recurring payment based on a set amount of weekly hours and time worked,
divided over a set number of pay periods. Governed by state wage and hour rules regarding
benefits, insurance, meal periods, and other formal accounting rules.

Work for the company

${ }^{8}$ It was clear upon our initial queries related to quantities of water consumed during the first focus group administration that Cohort members did not have a consistent way to convey actual measurements by volume. This resulted in significant variability in the answers received. As a result, these questions were removed from the moderator guide in subsequent focus group sessions. 
given the goal of frequent hydration encouraged as part of most heat-stress prevention outreach and training, including the OSHA campaign. Moreover, Cohort notions of hydration are more prominently linked with drinking beer or soda (see Table 5).

While looking at motivations for beverage choice, a larger trend began to emerge in relation to how workers describe cause-and-effect relationships between water consumption and regulation of body temperature, and between water consumption and illness. One participant from the Cohort described a relationship between water temperature and illness this way:

If the water is too cold and we are hot, we get sick. It is good to drink a little bit, because if we are very thirsty and drink a lot, we may get sick. But the water should be a little cold, because if it is hot, it does not help to drink it. So if we noticed that it is cold, we should drink little by little and that is fine but [if] we drink too much at once, it is not good. (Participant \#5, Farmworker Focus Group, August 9, 2013)

Many Cohort members also believe that shifting one's body temperature too rapidly could be dangerous and harmful to the body. This belief is expressed most often in relation to consuming

Table 5. Motivations and Choices for Beverage Consumption

\begin{tabular}{ll}
\hline Motivations & Beverages Consumed a \\
\hline Energized, feeling tired & - Energy drinks \\
& - Beer \\
& - Coffee \\
\hline Quench thirst & - Beer \\
& - Soda or Kool-Aid \\
& - Water \\
\hline Regulate body temperature, & - Beer \\
cool down & - Soda \\
& - Sports drinks (e.g., \\
\hline Feeling sick & Gatorade) \\
\hline Encouraged, directed by & - Water \\
employer & \\
\hline a Ordered by frequency of participant identification (highest to \\
lowest).
\end{tabular}

cold water and exposing the body to cold water when one's body temperature is elevated, as in showering or putting a soaked towel on the head:

For me in my case, it is bad because when it's [the water is] very cold and the temperature is too hot, because your body does, how do you say it, it goes haywire. When the temperature in your body is very hot then you throw something very cold on it, it breaks. (Participant \#5, Farmworker Focus Group, July 5, 2014)

A similar belief was also expressed, though less often, in anticipation of a changing external temperature or climate. For example, a temperature change for participants once they left home (cool) and arrived at work in the fields (hot) was viewed as dangerous to their health. Similar assertions were extended to a sudden move from hot outdoor temperatures to a place with air conditioning.

Only one pattern emerged around food consumption within the Cohort. Several participants identified eating melons (watermelons) as a refreshing food, one that can help to cool one down. The highly refreshing nature of the fruit was emphasized without reference to its water content $(92 \%)$. The majority of participants shared that they drink coffee in the morning before leaving for the fields, but only one participant gave any indication that something was eaten before reporting to work in the morning. Most packed lunches to eat later in the day and arrived at work on empty stomachs. Very few Cohort members reported drinking water before leaving for work. The dominant pattern of eating breakfast after reporting to work, combined with the preference for drinking soda or beer to cool down, only increases the likelihood that some farmworkers may start the day at an increased risk for HRI.

Descriptions of voluntary water consumption were limited and frequently conveyed as something you might do as a requirement of the job. There was also a recurring assertion among Cohort members that drinking water, in and of itself, could make someone sick. This was especially true if workers were feeling overheated. Moreover, water temperature was identified as a factor in 
exacerbating sickness. Concerns over taste (chlorinated flavor), odor (bad), and temperature (too warm or too cold) were consistently identified as rationales for avoiding drinking water. This was especially true for employer-provided water on-site in a cooler or jug. There was no consistent pattern, however, related to specific attitudes or beliefs about water provided on-site. Instead, a more consistent belief about water temperature, in general, was expressed. Cold water was reported to make people feel worse, including creating nausea. The motivation groupings found in Table 5 provide some additional architecture for interpreting this aversion to drinking water. Water was more frequently associated with negative experiences (feeling sick), or an external impetus (encouraged or directed by employer), possibly explaining some of the voluntary avoidance during the workday by Cohort members.

The findings on water and temperature change present a significant puzzle: the general acceptance within the Cohort that a beer, usually consumed cold, does not prompt the same concern about negative body reactions as does the consumption of cold water. Instead, cold beer is sought out when there is a desire to quench thirst, get more energy, or reduce exhaustion. This initial finding pushed our analysis to explore the linkages between such beliefs about water and other variables that may be shaping workers' behavior patterns related to water. Cohort members discussed a catalogue of behaviors that ultimately result in water avoidance. This proved fruitful in turning the analysis toward a clustering of factors that might better explain any choices to hydrate during the day and engage in general self-care.

\section{Self-Care Routines and Patterns}

Our data analysis was especially robust around the notions of self-care, which are defined as elective efforts to take rest breaks, seek shade, modify dress, and drink water. "Self-care" evolved into a larger code family that included care efforts that occur outside the workplace, at home, and even

\section{Figure 2. Eight Factor Clusters Related to Self-Care}

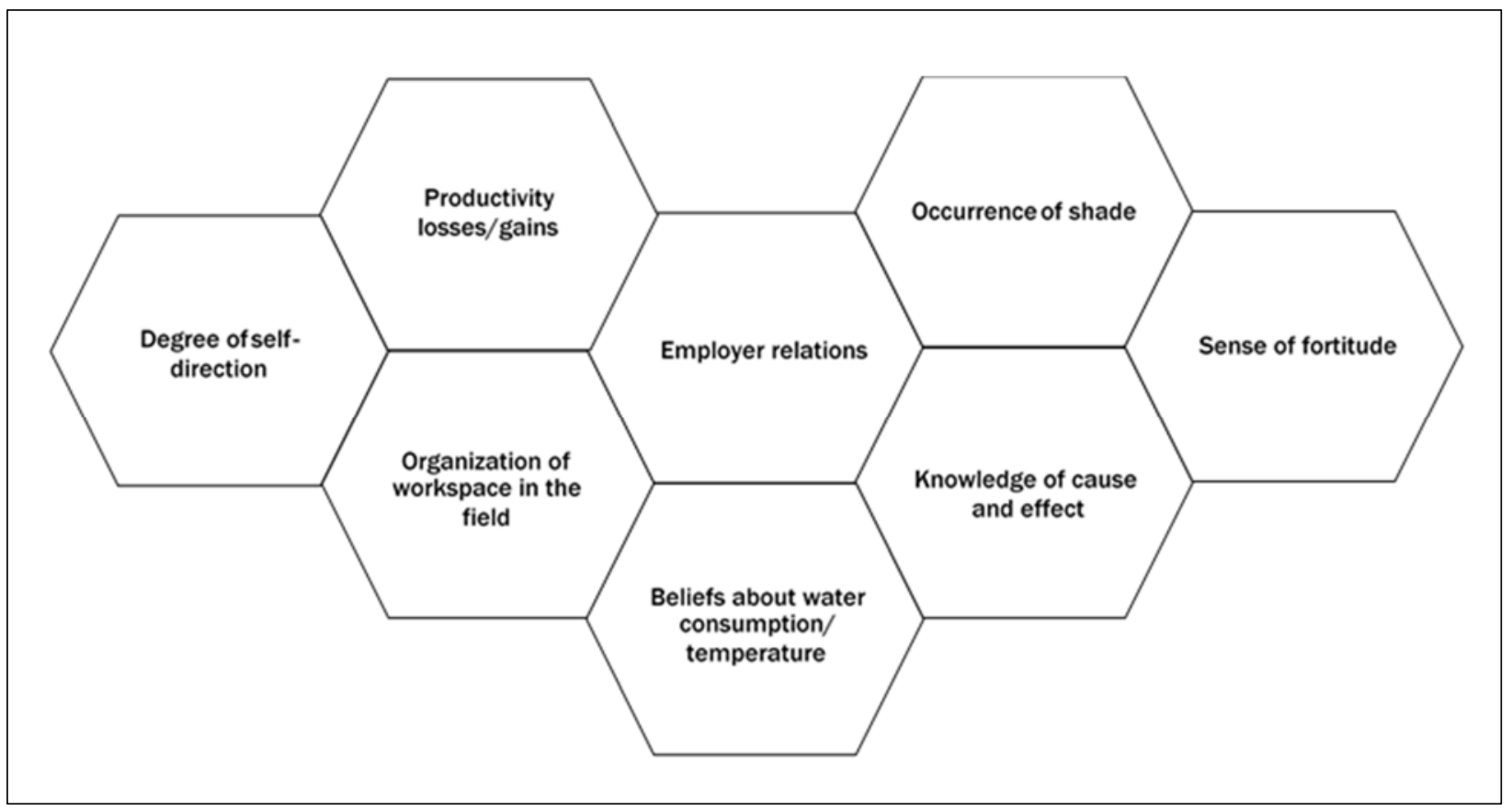

The honeycomb presentation helps to convey the associational relationships and complementarity of the eight factor clusters related to self-care. Each factor cluster can align with any other in a self-care decision. They are not grouped in any fixed position. Just as in a honeycomb structure, factor clusters are tightly connected together when shaping a self-care decision. 
during transportation to and from work. Self-care codes were the most commonly applied during the coding process, reflecting the degree to which participants discussed or identified these activities in relation to multiple prompts and a range of questions. The coded passages began to form a web of relationships that reveal a set of factor clusters that can help provide deeper understanding of the specific self-care actions and efforts participants describe or identify. This also points the way toward a better understanding of the contradictions of water consumption and temperature presented in the section above.

There are eight cluster factors: Beliefs about water consumption/temperature, Degree of self-direction, Employer relations, Knowledge of cause and effect, Occurrence of shade, Organization of workspace in the field, Productivity gains/ losses, and Sense of fortitude. Figure 2 presents, in no particular order, the eight factor clusters that combine in varying ways to shape the calculation of personal decisions to engage in self-care.

Each factor cluster was identified based on patterns of individual statements from participants and recurring themes within the focus group transcripts, threaded together by continuity in topic or subject. Consider, for example, the pattern that emerged to form the factor cluster Beliefs about water consumption/temperature, presented in Figure 3.

The factor clusters help conceptualize the many different influences and motivations that interact to shape Cohort behaviors and actions related to HRI prevention, safety interventions, and ongoing learning. Some factor clusters, such as the Occurrence of shade, capture the geographic and physical differences by harvest site and with regard to field terrain. Many participants noted that grape harvests, for example, provide some shaded areas under the vines - though not sufficient protection based on California law-while other crops such as strawberries are harvested in open fields without any trees or structures that cast a shadow. This factor cluster also reflects reported variability among employers on the provision of shade protection, including Cohort reports that some employers encourage breaks under trees within view of the work site. ${ }^{9}$

\section{Figure 3. Sample Factor Cluster Construction}

Moving from left to right, responses related to participants' beliefs about water are categorized into two shared subgroups that ultimately form a factor cluster.

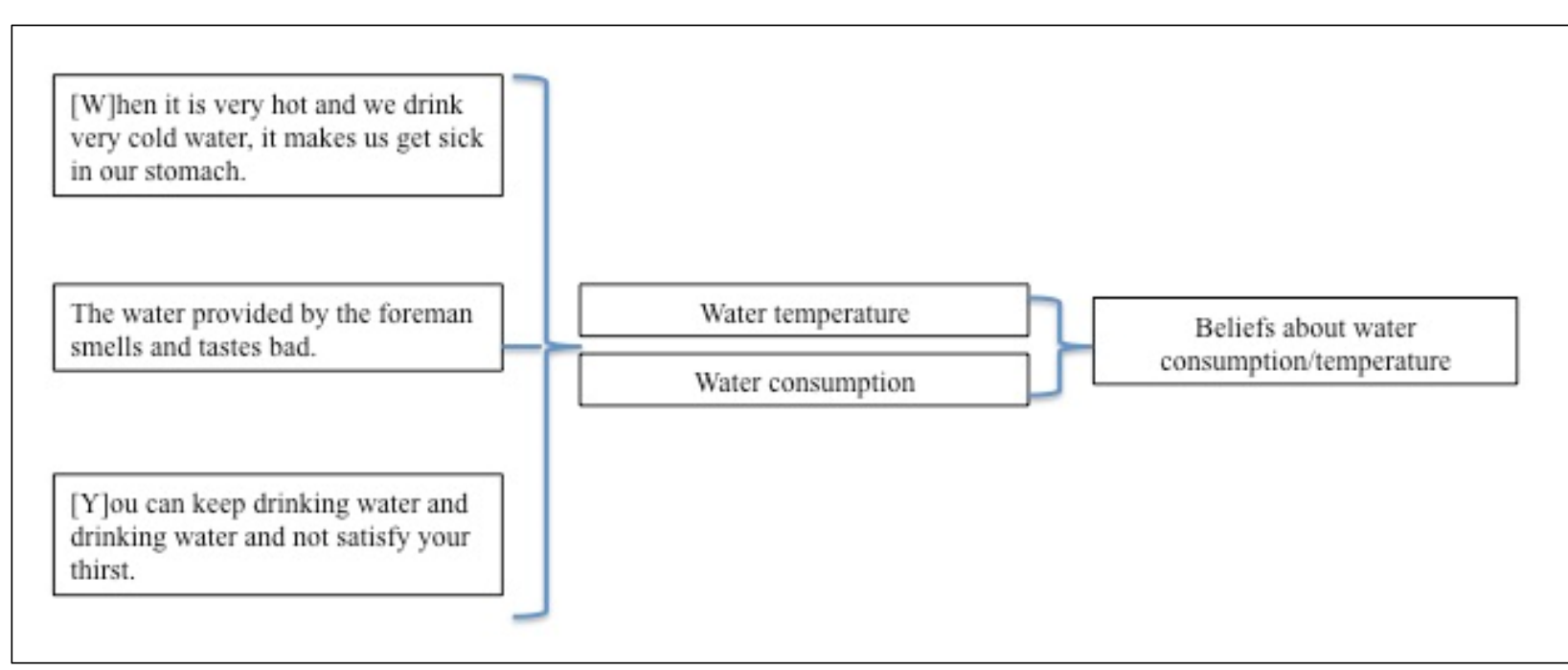

\footnotetext{
${ }_{9}^{9}$ Several participants noted that at times there is shade or water on the periphery of the harvest or work site, under a tree, but that those trees can still be quite far away. Some locations were up to half a mile $(.8 \mathrm{~km})$ away, requiring a 10 to 15 minute walk. A couple of
}

these same participants noted that the walk alone-on loose ground — could be dangerous if they are already feeling dizzy or ill (Participant \#4 and Participant \#5, Farmworker Focus Group, August 8, 2013). 
Cohort members described multiple patterns of interaction that point to the intersection of both worker agency (i.e., Sense of fortitude) and workplace structure (i.e., Organization of workspace in the field) in making self-care decisions. Some structural factors, such as Productivity losses or gains, cut across all self-care choices in a deep way. Participants frequently reported that they often predicate self-care decisions on this factor alone, as expressed by this Cohort member:

Yes, we just have to continue working, especially when it is piecework in order to earn more we continue to make our day. When we see that we have only earned 50 or 40 , we have to continue to reach at least 100, and then we take it easy, if not, then we continue, but if we feel bad, then we take a break. (Participant \#6, Farmworker Focus Group, June 14, 2013)

The factor clusters interact to shape worker choices in varying ways. Some, such as the consideration of piece rate described above by one participant, undercut the expressed desire to take a rest, even when there is a physical duress or awareness of HRI symptoms. Participants will assert their agency to "take a break," and then immediately counter that potential to act by repositioning the salience of a more structural factor cluster, which then deters them from acting:

Yes, we continue working because we want to advance to earn what we are supposed to for the day, when it is piecework, we have to continue working, until we can't handle it anymore. Even though the foremen place shades and ask us to drink water, they don't know our feelings that we want to continue working to earn a little bit more money and we just rest in the end. (Participant \#5, Farmworker Focus Group, June 14, 2013)

\section{Figure 4. Select Factor Cluster Groupings}

Select factor cluster groupings help illustrate how self-care decisions are shaped in relation to rest, shade, and water while working in the fields.

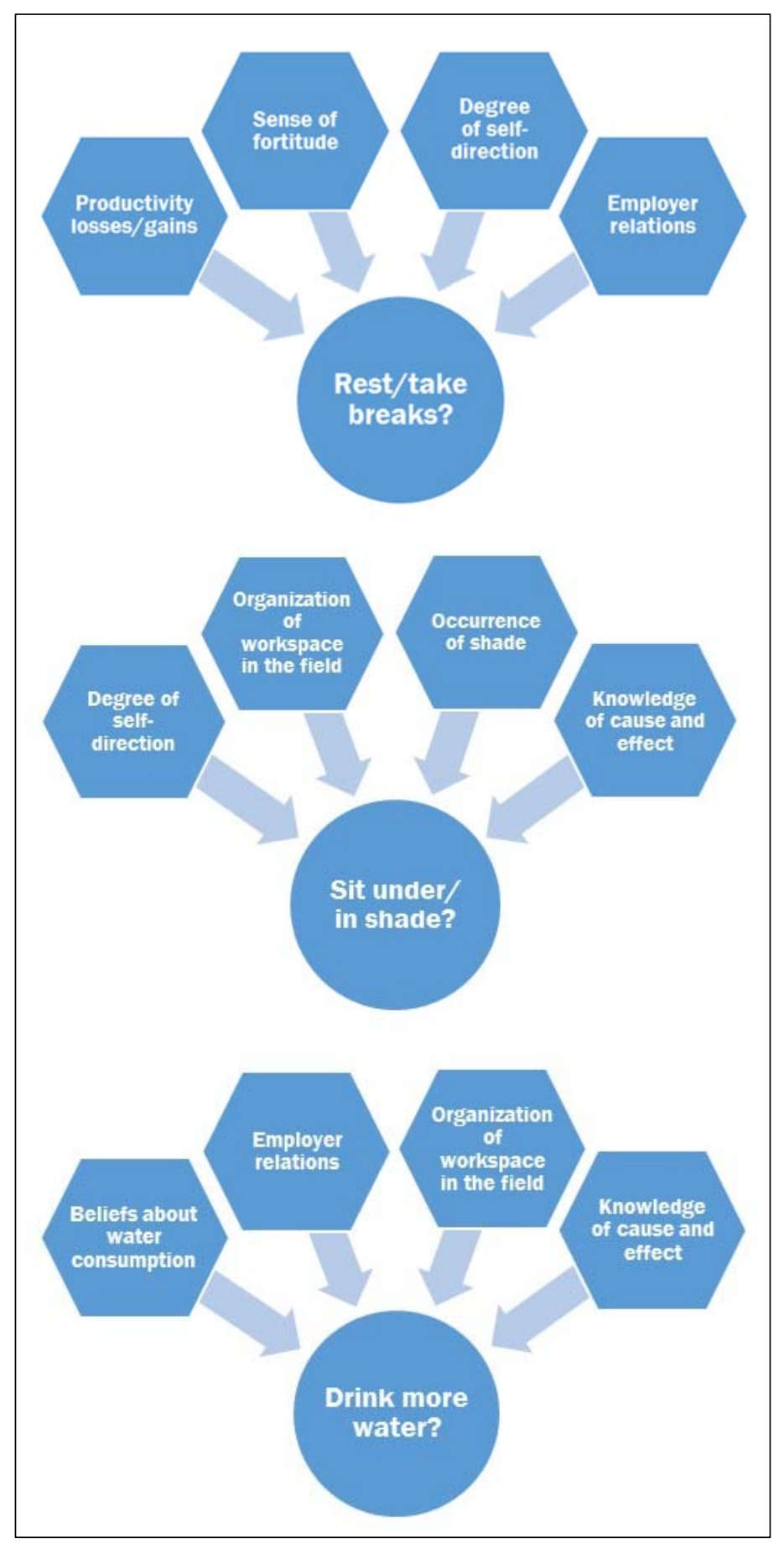

These agency-structure dynamics cannot be fully explored in this paper, but Figure 4 reflects 
some of the more robust patterns related to the three primary self-care practices—rest, shade, and water-to further illustrate such dynamics.

\section{Worker Knowledge and Perceptions of HRI}

Participant discussions of HRI symptoms and its potential fatality generated a unique set of patterns related to both the knowledge of symptomology and personal beliefs about illness. Table 6 displays an inventory of the medically recognized HRI symptoms identified by Cohort members. Men and women expressed largely overlapping inventories of symptoms, but the frequency of some identified symptoms varied by the gender of focus group participants.

Although not recognized as symptoms by $\mathrm{NIH}$, participants also associated the following with HRI: turning pale, heartburn, nose bleeds, flu, diarrhea, and pregnancy. Coding and conceptual mapping generated a more textured view of Cohort assumptions and beliefs about vulnerability to HRI and their own personal sense of fortitude. While clearly not a symptom of any illness by traditional standards of Western medicine, the mention of pregnancy by some participants was associated with a state of vulnerability or weakness. This, in turn, prompted a belief about susceptibility to HRI, or any illness for that matter. While less pronounced among participant women, there is still a sense that some people are just less healthy or more delicate by constitution. Women and young people, as a group, are identified as those more susceptible to illness. This is associated with their essential nature of being a woman, a young child, or an adolescent. At the same time, participants frequently describe HRI-susceptible individuals as those with a "weaker" constitution, or those "sick" with another illness such as diabetes. This finding held true across all five focus groups. However, it is the exclusion of men as a group from such categorizations of "vulnerability" that is most striking across the focus groups, and it raises sensitivity to the ways that gender may shape and reshape the notions of prevention, vulnerability, and susceptibility to heat stress for this population. ${ }^{10}$ This finding also reinforces the role that a Sense of fortitude may play in shaping self-care decisions.

\section{Perceptions by Gender}

One interesting pattern of note is the gendered reporting of symptoms. In general, women describe early onset HRI symptoms, as well as a wider range of symptoms, from dizziness and
Table 6. Inventory of Identified Symptoms Related to HRI

\begin{tabular}{lcc}
\hline Cohort Identified Symptoms a & $\begin{array}{c}\text { Most Frequent } \\
\text { Within the Cohort }\end{array}$ & $\begin{array}{c}\text { Association } \\
\text { by Gender }\end{array}$ \\
\hline Blurry vision & Women \\
\hline Body aches & Women \\
\hline Chills & $X$ & \\
\hline Cramps & $X$ & Men \\
\hline Crying & $X$ & \\
\hline Dizziness & & \\
\hline Dry skin & & \\
\hline Excessive sweating & Men \\
\hline Fainting or "falling out" & & \\
\hline Feeling bad & & Men \\
\hline Thirst & & \\
\hline Anger or short temperedness & \\
\hline Headache & & \\
\hline Fast heartbeat & & \\
\hline No urge to work; fatigue & & \\
\hline Rash & & \\
\hline Sick to the stomach or vomiting & & \\
\hline Sunburn & & \\
\hline This includes only those symptoms documented by the National Institute of \\
\hline
\end{tabular}

${ }^{10} \mathrm{It}$ is the omission of men in comparison to "women" and "youth" as a group of vulnerable individuals that was striking. Participants noted differences in behavior that they believed put individuals at risk (those who drink, those who eat poorly and are overweight), and these individuals could be either men or women. The focus here is on the essential characteristics of groups, tied to a belief in a Sense of fortitude, in which some people are believed to just be "built" to work, while others are less naturally capable. 
vomiting to cramps. Men, on the other hand, tend to identify later symptoms such as fainting or falling as the primary symptom or evidence of an illness. There were also a few references to women serving as supervisors in the fields (forewomen), from whom the participants indicate a more caring or vigilant approach to encouraging worker self- care, especially drinking water while in the fields. This could be another indicator of gendered forms of symptom awareness and prevention.

Discussion excerpts presented in Table 7 help to parse out these gendered differences in symptom identification and awareness. Excerpts are drawn from two gender-specific groups and

\section{Table 7. Comparison of Symptom Discussion by Gender a}

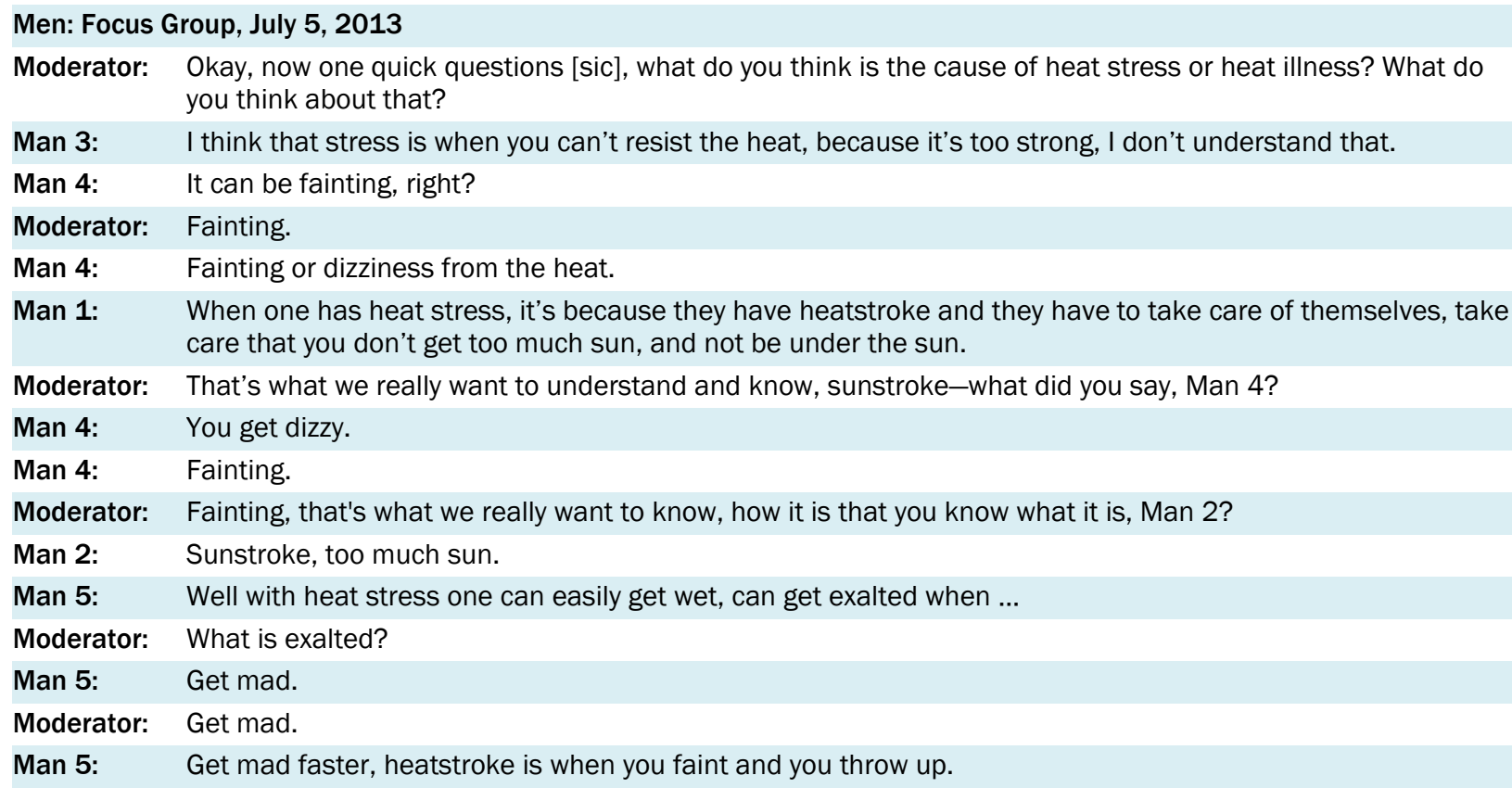

\section{Women: Focus Group, August 8, 2013}

Moderator: You have heard of heat stress?

All Women: Yes.

Moderator: Okay, what do you think it is?...

Woman 1: Fatigue.

Moderator: Fatigue, you've already told me. What is it that you interpret as heat illness?

Woman 1: Headache.

Woman 3: Vomit.

Woman 5: Body aches.

Moderator: Body aches. What else?

Woman 4: Chills.

Moderator: Chills. What else?

Woman 4: Tiredness.

Woman 6: Cramps.

Moderator: Cramps, dizziness, stomach pain, blurred vision, dizziness-

Woman 9: Very strong palpitations in the head and heart.

Moderator: Do you believe that this can also cause death?

All Women: Yes.

a The excerpts presented here have been edited grammatically for clarity. 
compared side by side. By displaying the conversation threads in this manner we can observe a gender-based pattern. Women tend to describe a wider range of symptoms, and as noted in Table 7, they include more early-level symptoms like cramping and fatigue in their identification. Men, on the other hand, tend to focus on later-level symptoms as indications of heat illness, which is important to keep in mind given that the symptoms they more frequently identify are those associated with late stages of HRI: nausea, fainting, and anger and/or irrational behavior. Men more frequently than women identified fainting or falling as the most significant indictor that someone was ill, though not necessarily suffering from HRI. One male participant's statement in particular captures this emphasis on fainting or falling as the indicator of heat illness, even though there is acknowledgement of other factors that may have contributed to the ultimate effect of passing out:

One day we were working and a woman who was covered up fell and they took her, two or three weeks later another man fainted for the same reason, because of the symptoms. Most always when it is really hot people fall and faint, but sometimes I don't know, they're not well informed. (Participant \#4, Farmworker Focus Group, June 13. 2013)

\section{Worker Training and Education}

Participants reflected upon their training experiences and their level of workplace education related to HRI. The level and degree of formal training that participants had received was hard to gauge. Verbal informationsharing from employers to workers, and between workers, seemed like the most common form of education. Information-sharing was a consistent enough practice across the Cohort that most workers had at least heard about formal and/or legal HRI protections. However, verbal informationsharing did not seem to provide accurate information related to HRI symptoms and prevention practices. Cohort members often suggested that the use of videos to learn about HRI prevention would be helpful, underscoring the potential value of seeing on screen how a farmworker can respond to HRI emergencies.

When asked whether they were "given training" by their employer about any number of topics related to HRI, the participants often stated they were told or advised by their employer or supervisor to "drink water" or "take rests" if they "feel dizzy" or "feel sick."

Training experiences described by the majority of participants (e.g., reading paper pamphlets, receiving flyers to take home) are not indicative of promising practices for worker safety education (Burke et al., 2006). The range of education and training experiences clustered more prominently around the informal modes of learning (see Figure $5)$.

Cohort members made frequent references to information-sharing in the workplace-simple statements about heat stress offered up periodically through a one-way exchange, either worker-toworker or employer-to-worker. Several participants in the Mixteco-language focus groups identified worker-to-worker information-sharing on heat

\section{Figure 5. Modes of Worker Education and Training}

Instructional classes with visual materials and pre- and post-tests

Review of posted signs, printed handouts, or placards

Distribution of printed handouts and written materials

Employer-to-worker information giving

Employer announcements

Public service announcements: radio, newspaper, etc.

Worker-to-worker information-sharing

\section{Formal Modes}

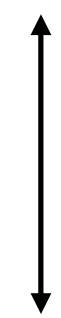

Informal Modes 
protection techniques as a specific form of training. This contrasted with the Spanish-language groups, where the notion of worker-to-worker information-sharing seemed hindered by a strong sense of worker independence. For the Mixteco-language groups, the desire was expressed to inform relatives and others arriving from a shared village or region of origin within Mexico upon arrival in the San Joaquin Valley about the challenges of working in the heat.

When there are people who still don't understand [how hot it will get], and those of us who have been living here for a long time, we should talk to them, because there are some who do not understand, yet. We should talk to them, "this is how it is here," "it is hot," and "we should work this way." We can talk to them and they will understand. Because it is so hot, when people are arriving from Mexico, they feel the heat. (Participant \#2, Farmworker Focus Group, August 9, 2013)

Employer information-sharing is the more frequent Cohort member experience. Sometimes such interactions take the form of directives such as "drink water" or "be sure to take a rest."
However, these are not to be confused with levels of formal training that allow for interaction and exchange between participants and a trainer, to cultivate new knowledge or bring about individual behavior change. The more common, informal experiences in acquiring information about HRI and worker suggestions on teaching methods, prompted us to take a closer look at how members of the Cohort actually make sense of new information and who they experience learning more generally.

\section{Learning and Worker Beliefs}

Some participants describe interactions with their supervisors that include an acknowledgement of their rights as workers to ask for shade or take a break under high temperatures. Many participants acknowledge that their awareness of these rights resulted from some form of information-sharing or, in a few cases, formal training they received from their employer. However, Cohort members also convey a sense of conflict in the exercise of those rights. Beliefs about productivity, personal fortitude, and illness interact in ways that subvert some worker efforts to exercise their rights and more openly identify early symptoms of HRI. Figure 6 helps to illustrate the relationship among beliefs, self-perceptions, and learning as expressed

\section{Figure 6. Relationship Among Beliefs, Self-perceptions, and Learning as Expressed in Focus Group Interviews}

Moving from left to right, the darker-shaded boxes indicate internal calculations that occur as new information is reconciled with competing beliefs and perceptions. A corresponding factor cluster for each calculation is presented in parenthesis.

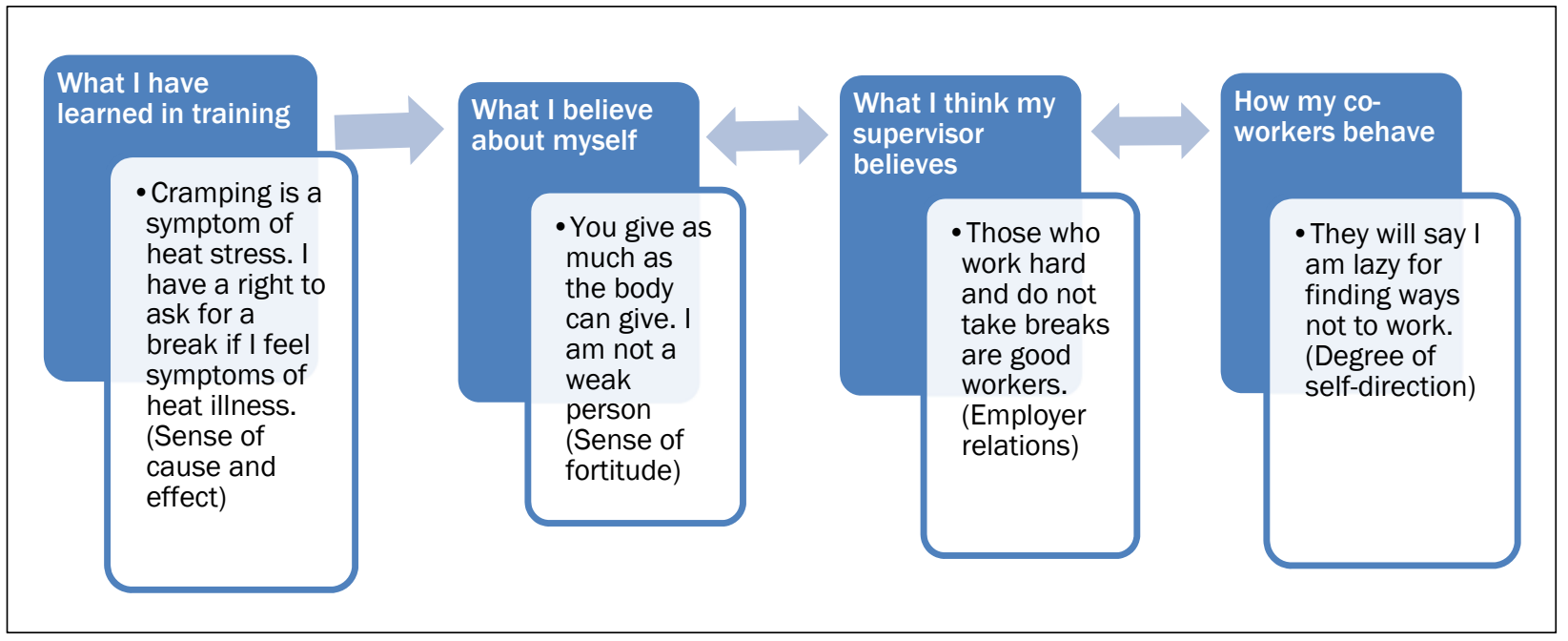


throughout the focus group interviews.

Drawing upon an example from participant discussions related to workplace rights, the linkage between beliefs, perceptions, and learning becomes clearer. We found evidence of such internal calculations and weighing of beliefs throughout the focus group discussions. This example also helps to elevate some of the complexities behind workers' behaviors to prevent HRI and to intervene on behalf of others when health is at risk in the field, and it further illuminates the interaction of factor clusters, which shape self-care actions (see again Figure 3). Plotting the corresponding factor clusters for each belief and/or perception further elaborates the degree of interaction operating behind farmworkers' behavioral choices. The more common informal learning and informationsharing experienced by Cohort members might privilege some factors over others when participants make calculations about HRI prevention, such as an overreliance on the Degree of selfdirection. This may come at the expense of minimizing others such as Knowledge of cause and effect, which could be lifesaving if given more weight in such calculations.

\section{Overarching Structural Factors and Patterns}

Two overarching structural patterns cut across all focus group sessions. We will discuss each to better understand how these structures shape worker experiences and how they might pose significant challenges for interventions aimed at changing individual HRI prevention behaviors. The first pattern is tied to the structure of payments and the location of Cohort members within the labor force. The second pattern elevates the interplay of worker control and employer relations in the workplace. Intersecting with these patterns are what may be referred to as misconceptions and folk beliefs about health and illness. This presents a third complementary pattern, which will be explored concurrently given the mutual interaction it had with the two larger structural factors.

\section{Pay Structure and Worker Productivity}

The majority of the participants are paid under a contract at piece rate (see again Table 4). Some participants in the cohort referred to this pay scheme as "by contract," and this is contrasted with work "by hour," even though the latter can also be performed under a contract. The benefit of a piece rate to growers is clear: they have a workforce that is motivated to rapidly complete the tasks at hand. This pay scheme benefits the employer, who may be under pressure to fulfill contracts that stipulate a certain standard related to fruit and vegetable quality or maturity, to avoid sudden changes in the weather that can damage crops, or to complete a harvest to meet high seasonal market demands. Cohort members insist that piece rate is the preferred pay scheme in relation to cumulative earning potential. However, this preference for piece rate is less clear-cut than it appears on its face. The economics of low-wage agricultural employment create a false choice between the lure of earning more money, faster, under piece-rate agreements, and the desire for more stable hourly wage opportunities. Yet given how hard the work is on the body and the high temperatures workers must endure, participants see trade-offs with both forms of payment (see Table 8). For example, there is a trade-off between the range of personal control (high for piece rate) and the opportunity to make more preventative selfcare decisions (low for piece rate). A closer look at such trade-offs between pay schemes will help to further explain the preference for piece rate work found among the Cohort.

The conversational nature of the focus groups presented some limitations to understanding the specific variables at play for workers earning an hourly wage. Nonetheless, it was possible to identify patterns regarding hourly wage agreements.

Table 8. Comparison of Worker Considerations by Pay Schemes

\begin{tabular}{lcc}
\hline \multirow{2}{*}{ Worker Considerations } & \multicolumn{2}{c}{ Degree of Occurrence } \\
\cline { 2 - 3 } Earning potential & Piece Rate & Hourly \\
\hline Sense of fortitude & High & Low \\
\hline $\begin{array}{l}\text { Preventative, self-care } \\
\text { decisions }\end{array}$ & High & Moderate \\
\hline Range of personal control & High & Moderate \\
\hline Risk potential & High & Low \\
\hline
\end{tabular}


Participants conceptualized the hourly supervisor as more paternalistic, directly responsible for determining how they work, when they take breaks, and when they are finished. The range of personal control under hourly wage agreements is viewed as quite low.

When asked about the frequency of formal training, encouragement to take breaks, reminders to drink water, and having access to shade, hourly wage agreements were identified as the form of employment where these preventative practices were most common. Participants also convey a sense that hourly workers are asked to work longer hours without having a choice of when to "call it a day."

I know some people that go to work and when they come back home, they don't have the strength or when they don't drink water, when they get back home in the evening, they get very thirsty and they want to drink a lot of water and they said that they don't have strength because they work too much. When they work per hour, nobody tells them to get off and go home. When they are working piece rate, they can get off of work at any time they want... (Participant \#1, Farmworker Focus Group, August 9, 2013)

Yet this asserted worker agency to "leave when they want" under piece rate is not consistent with the profile of self-care decision-making described above, and the tendency to choose higher earnings over voluntary rest periods. Taking a break or rest while getting paid by the piece means that the worker, in essence, is paying for the idle time through loss of output, while the employer pays for the idle time when a worker is paid by the hour. This often pushes workers to experience feelings of compulsion to ignore the self, to subordinate the body to the rhythms and pace of the harvest.

No, most [hourly jobs] don't pay. Like us where we are, it is by contract, people give as much as the body can give. If people know they can't go on, they sit, but because it's by contract, one gives as much as the body endures, because the more you deal, the more you make. You earn more and then... (Participant \#2, Farmworker Focus Group, August 8, 2013)

So, while hourly wage earners are likely to benefit from a set of prescribed safety rules, workers feel subordinated to the directives of the employer. In this way, hourly agreements undercut the subjective sense of control that workers value, fix wages at lower cumulative rates, and diminish the degree of fortitude that can be expressed at work. This better explains the participant assertion that piece rate work is preferred, despite the heightened tendency under such pay schemes to subordinate self-care to the demands of the harvest. Still further, the desire expressed by many participants to be recognized as hard workers with great fortitude, and the perceived employer interest in hiring fast, low-maintenance workers, tends to reduce the likelihood that participants stop working and assert the right to self-care. At minimum, an assertion of such rights requires that general worker knowledge of illness and HRI symptoms is sufficient to supersede reliance on folk belief systems related to health and misconceptions about body function (e.g., the deleterious effects of cold water on a hot body). Moreover, Cohort experiences suggest that employer investments in training to correct HRI knowledge deficits are uneven at best. In this way, control of the labor force is buttressed through the maintenance of misconceptions about HRI and the perpetuation of folk beliefs related to the body and health. The interplay between pay structure and worker belief systems within the Cohort data is consistent, and this indicates a significant barrier to preventing future HRI deaths.

\section{Employer Relations and Worker Control}

Individual experiences with employers varied to a certain extent, but some recurring themes related to employer relations did emerge. Participant descriptions of employers fall into two very broad categorizations of caring employers and uncaring employers. Caring employers were described as having some personal investment in the agricultural business at hand, like a rancher or a farm owner. 
Those described as not caring were most often farm labor contractors and farm businesses that hired "by contract." This dichotomous view of employers reflects the experience of many lowwage employees in a variety of sectors. Yet for the Fresno Cohort it was also tied to a set of complementary concepts about worker control.

An array of codes clustered around the level of worker control and relationships to supervisors. If being paid by the piece, supervisors were viewed as a drag on the potential to earn wages, interrupting workers with encouragements to take breaks or water, detracting from their potential time to make more money. Further evidence of this dynamic is found in the large number of participants who bring their own water to work sites, in order to limit idle time when paid by the piece and to maintain more control over the length of their work day. Conversely, hourly wage employees described supervisors in terms of being either caring or not caring, a distinction from piece-rate employer relationships, which are most often portrayed as disinterested in worker well-being. Moreover, relationships with farm labor contractors in a supervisory role are consistently identified as strained regardless of the pay structure.

Participants also referred to requirements or directives by any supervisor to take breaks, drink water, or seek shade as impositions when paid piece rate, and acts of compliance when paid hourly. The function of the supervisor is viewed differently depending on the pay structure. The shifting interpretation of supervision, however, should not obscure the larger categorization participants make between employers who care and those who do not care. This was further supported by the fact that it mattered a great deal to participants how a foreman, forewoman, or supervisor expressed or acted upon a rule. Having an information-sharing session before a workday conveyed some sense that the employer cared for workers. Voluntarily bringing water to the workers in the field and offering them a drink was also described as an attribute of a more caring employer, although that had no clear relationship to a worker's willingness to drink the water offered. Here again the notion of control and choice still underpinned self-care decisions and worker beliefs.

Another aspect of worker control and employer relations emerged in conjunction with a worker's position within the labor force. Participants' descriptions of health knowledge and their own calculus for pursuing self-care was reconfigured as their position in the workforce changed. For example, participants who occupied a position as a supervisor or tractor driver spoke more consistently about taking breaks and having more knowledge of HRI prevention. There was a more prevalent emphasis on taking breaks, drinking water, and leveraging knowledge of cause and effect related to health, for the few members of the Cohort who received a salary. Individual control seems to interact with the increased level of worker knowledge about cause and effect, thus reconfiguring control as worker self-direction to avail oneself of existing workplace protections and regulations.

\section{Conclusions}

A synthesis of findings from the CHIPS Fresno focus groups calls into question current methods used for training and education to prevent HRI. The data have helped to develop a model of interactive and adaptable relationships among worker behaviors, beliefs, and low-wage agricultural work structures that can guide future research. The factor clusters discussed present a complex architecture that workers use to decide on self-care actions. Convincing workers to take action to prevent HRI is the ultimate aim of training. It is therefore important to understand how relationships between identified factor clusters interact when different HRI intervention and prevention strategies are deployed, and to isolate those clusters that can be modified through policy change, more comprehensive worker education, and/or the use of new technologies.

\section{Drinking and Eating Habits}

Findings related to drinking and eating highlight a complex interplay of factors in self-care decisions. While a gap in worker knowledge may have some role in shaping Cohort hydration practices, there is clear evidence that most participants knew that 
they should drink while working in the fields, especially when working rapidly at piecework.

This points to beliefs about the properties of water and the functioning of the human body that better explain part of what may deter workers from drinking water. While it is sound practice to train farmworkers to increase water consumption, there is little evidence that drinking water is part of the everyday behavioral practices of field workers. Still further, the act of drinking water manifests more often as something identified as a requirement of the employer or a requirement of the job, an imposition from a source of power and control rather than an internal impetus. Patterns related to water consumption point to other complex variables that determine what action workers take toward self-care.

\section{Self-Care Routines and Patterns}

The eight factor clusters presented in Figure 3 generate a nuanced view of the dynamics that affect farmworker self-care. While we cannot determine the frequency or degree of influence on individual decisions for each factor cluster, they are useful as applied theoretical tools for understanding potential interactive relationships. For example, focus group data show that the majority of Cohort members understand, on some level, the importance of drinking water, taking rests, and seeking shade throughout the workday. However, the factors that shape individual decisions to actually pursue actions point to more dynamic, interactive patterns of decision-making.

\section{Worker Knowledge and Perceptions of Heat Illness}

A more general sense of cause and effect of illness is probably better understood as a set of beliefs about how the body responds to environmental conditions, including changes in temperature. It is not necessarily true that the workers are unaware of HRI as a real phenomenon, but our findings suggest that training related to causes and symptoms of HRI might not get cognitively organized in ways that are directly linked to cause and effect.

\section{Perceptions by Gender}

The observed gendered awareness of symptoms has significant implications for farmworker training on heat stress. If women are more likely to be attuned to lower-level signs of heat illness and men are less attuned, the scope and emphasis on symptom presentation in training should be modified to reflect this difference between the genders. In addition, men may not approach intervention at the earlier stages of heat illness. Further exploration of beliefs tied to the notion of limited male vulnerability, combined with a sense of emergency around only the most severe symptoms of heat stroke (e.g., falling, fainting), seems warranted.

\section{Worker Safety Training and Education}

Participant experiences point to more informal modes of worker education as the more common experience in the field. These more informal modes of education and training often rely on the distribution and voluntary review of printed materials. Handouts identified as most engaging to farmworkers were those with full-color pictures and designs. However, according to most participants, printed materials are often ignored or not read in full. The other key finding related to educational outreach efforts was that most participants identified videos as the preferred medium for delivering training content.

\section{Learning, Beliefs, and Worker Perceptions}

A more formal study of the model generated here will be explored in future research to isolate some of the variables and processes that increase the likelihood that farmworkers will act to prevent HRI. In addition to the insights gained from this review of the subjective participant experiences, the coded data also elevate some structural factors that affect the shared experiences of the farmworker Cohort.

\section{Overarching Structural Factors and Patterns}

Not only does the organization of piecework itself undercut efforts to keep workers safe, it also reinforces workers' misconceptions and beliefs about their bodies and health, in ways that benefit the employer. Notions of worker control convolute efforts to engage in self-care and take timely action to address HRI symptoms. The incentive to demonstrate fortitude in the workplace even when 
suffering from early symptoms of heat illness is best understood as a coping mechanism and response to the structure of pay in the sector. The risk with this compensatory strategy for workers is that it can ultimately take a person out of the earnings arena altogether, if health and safety are compromised in the process.

As position in the labor force changed for participants, so did their description of health knowledge and their own calculus for pursuing self-care. This pattern aligns with research by Theorell (2003) showing a relationship between increased levels of worker control and improvements, and the overall health of the worker.

More direct exploration of worker beliefs and habits under hourly wage agreements could help to identify implications these perceptions might have for worker health and safety. Nonetheless, the data presented a profile of worker and employer relations that orbit around the level of worker control. Still further, by leveraging subjective worker views about their own sense of fortitude, employers reproduce a preference among workers for pay structures that diminish production losses while encouraging worker risk-taking. This finding harmonizes with Holmes (2013) and Thomas (1985), asserting the interplay of worker identity and workplace practices to explain the persistence of workplace inequalities and worker risk-taking related to health prevention.

The other potential target for change that arises from this study is the behavior of farm labor contractors, as they play a significant role in the employer relation factor cluster. Cohort views of relations with contractors further affirm findings from Majka \& Majka (1982) and Wells (1996) related to the advent and prominence of labor contractors in California agriculture as an intransigent impediment to improved conditions for lowwage agricultural workers. Our preliminary findings underscore the structural relations of agricultural employment that will continue to undercut strategies focused solely on behavior change to ensure HRI prevention, regardless of whether that change is among workers or employers. The findings from the Fresno Cohort point to the salience of employer relations in the worker calculus to pursue or consider self-care regimens.
Future CHIPS focus groups will continue to explore the theme of employer relations and selfcare, given the initial findings presented here. These findings may assist in future investigations of how time spent in the field relates to individual responses to and construction of coping mechanisms for heat exposure and how individuals learn about HRI prevention. Taken together, the initial findings from the Fresno Cohort identify pay structures, employer relations, and subjective worker views (e.g., worker control, sense of fortitude, misconceptions about body function) as the most appropriate targets for change to bring about longer-term improvements in farmworker health.

\section{Acknowledgments}

JBS International provided focus group facilitation, transcription services, and language translation. Centro Binacional para el Desarrollo Indígena Oaxaqueño provided participant recruitment and screening services in the Fresno area.

\section{References}

Aldrich, M. (1997). Safety first: Technology, labor and business in the building of American work safety, 1870-1939.

Baltimore, Maryland: Johns Hopkins University Press.

Burke, M. J., Sarpy, S. A., Smith-Crowe, K., ChanSerafin, S., Salvador, R. O., \& Islam, G. (2006). Relative effectiveness of worker safety and health training methods. American Journal of Public Health, 96(2), 315-324. http://dx.doi.org/10.2105/AJPH.2004.059840

California Department of Industrial Relations. (2007, October 18). Cal/OSHA investigations of heat-related illness 2006 [Letter to Len Welsh, Acting Chief]. Division of Occupational Safety and Health. Retrieved from https://www.dir.ca.gov/dosh/ heatillnessinvestigations-2006.pdf

California Department of Public Health. (2008). Public health climate change adaptation strategy for California.

Retrieved from https://www.cdph.ca.gov/ programs/CCDPHP/Documents/CA Public Health Adaptation Strategies final.pdf

California Heat Illness Prevention Regulation, Title 8, Article $10 \$ 3395$ (2010). 
Centers for Disease Control and Prevention [CDC]. (2008). Heat-related deaths among crop workers --United States, 1992-2006. Morbidity and Mortality Weekly Report, 57(24), 649-653. Retrieved from http://www.cdc.gov/mmwr/preview/mmwrhtml/ $\underline{\mathrm{mm} 5724 \mathrm{a} 1 . \mathrm{htm}}$

Cohen, A., \& Colligan, M. J. (1998). Assessing occupational safety and health training: A literature review (DHHS Publication No. 98-145). Retrieved from National Institute for Occupational Safety and Health website: http://www.cdc.gov/niosh/docs/98145/pdfs/98-145.pdf

Duke, M. (2011). Ethnicity, well-being, and the organization of labor among shade tobacco workers. Medical Anthropology, 30(4), 409-424. http://dx.doi.org/10.1080/01459740.2011.576727

Fairris, D. (1998). Institutional change in shopfloor governance and the trajectory of postwar injury rates in U.S. manufacturing, 1946-1970. Industrial and Labor Relations Review, 51(2), 187-203. http://dx.doi.org/10.1177/001979399805100202

Georgakas, D., \& Surkin, M. (1999). Detroit: I do mind dying: A study in urban revolution. Cambridge, Massachusetts: South End Press.

Grzywacz, J. G., Alterman, T., Gabbard, S., Shen, R., Nakamoto, J., Carroll, D. J., \& Muntaner, C. (2014). Job control, psychological demand, and farmworker health: Evidence from the National Agricultural Workers Survey. Journal of Occupational and Environmental Medicine, 56(1), 66-71. http://dx.doi.org/10.1097/jom.0000000000000025

Guthman, J. (2004). Agrarian dreams: The paradox of organic farming in California. Berkeley: University of California Press.

Holmes, D. R. (1989). Cultural disenchantments: Worker peasantries in Northeast Italy. Princeton, New Jersey: Princeton University Press.

Holmes, S. M. (2013). Fresh fruit, broken bodies: Migrant farmworkers in the United States. Berkeley: University of California Press.

Karasek, R., \& Theorell, T. (1990). Healthy work: Stress, productivity, and the reconstruction of working life. New York: Basic Books.

Knights, D. (1990). Subjectivity, power and the labour process. In D. Knights \& H. Wilmot (Eds.), Labour process theory (pp. 297-335). London: MacMillan.

Knights, D., \& Willmott, H. (Eds.). (1990). Labour process theory. London: MacMillan.
Lam, M., Krenz, J., Palmández, P., Negrete, M., Perla, M., Murphy-Robinson, H., \& Spector, J. T. (2013). Identification of barriers to the prevention and treatment of heat-related illness in Latino farmworkers using activity-oriented, participatory rural appraisal focus group methods. BioMed Central Public Health, 13(1), 1-12. http://dx.doi.org/10.1186/1471-2458-13-1004

Landrine, H., \& Klonoff, E. A. (2004). Culture change and ethnic-minority health behavior: An operant theory of acculturation. Journal of Behavioral Medicine, 27(6), 527-555. http://dx.doi.org/10.1007/s10865004-0002-0

Lobao, L. M. (1990). Locality and inequality: Farm and industry structure and socioeconomic conditions. Albany: State University of New York Press.

Majka, L. C., \& Majka, T. J. (1982). Farm workers, agribusiness, and the state. Philadelphia, Pennsylvania: Temple University Press.

Mann, S. A. (1990). Agrarian capitalism in theory and practice. Chapel Hill: University of North Carolina Press.

Martin, P. (2009). Importing poverty?: Immigration and the changing face of rural America. New Haven, Connecticut: Yale University Press. http://dx.doi. org/10.12987/yale/9780300139174.001.0001

Martin, P. Y. (2003). "Said and done" versus "saying and doing": Gendering practices, practicing gender at work. Gender and Society, 17(3), 342-366. http://dx.doi.org/10.1177/0891243203017003002

Martin, P., Fix, M., \& Taylor, J. E. (2006). The new rural poverty: Agriculture and immigration in California. Washington, D.C.: Urban Institute Press.

McCarthy, J. J., Canziani, O. F., Leary, N. A., Dokken, D. J., \& White, K. S. (Eds.). (2001). Climate change 2001: Impacts, adaptation, and vulnerability. Cambridge, UK: Cambridge University Press.

McMichael, P. (Ed.). (1994). The global restructuring of agrofood systems: Food systems and agrarian change. Ithaca, New York: Cornell University Press.

McWilliams, C. (1935). Factories in the fields: The story of migratory farm labor in California. Berkeley: University of California Press.

Mendeloff, J. M. (1979). Regulating safety: An economic and political analysis of occupational safety and health policy. Cambridge: Massachusetts Institute of Technology Press. 
Mines, R., Nichols, S., \& Runsten, D. (2010). California's indigenous farmworkers: Final report of the Indigenous Farmworker Study (IFS) to The California Endowment. Retrieved from http://www.crla.org/sites/all/ files/content/uploads/pdfBrochures/IFS Mines Final 2010.pdf

Mines, R., Ward, C. C., \& Schenker, M. B. (2000). Prior enumeration: A proposal for enhanced sampling for farmworker surveys. Statistics in Medicine, 00, 1-6. Retrieved from https://rickmines.files.wordpress. com/2011/12/prior-enumeration-unpublished2007.pdf

Mirabelli, M. C., Quandt, S. A., Crain, R., Grzywacz, J. G., Robinson, E. N., Vallejos, Q. M., \& Arcury, T. A. (2010). Symptoms of heat illness among Latino farmworkers in North Carolina. American Journal of Preventative Medicine, 39(5), 468-471. http://dx.doi.org/10.1016/j.amepre.2010.07.008

Rao, P. (2007). Heat related illnesses: An occupational health concern for farmworkers. Washington, D.C.: Farmworker Justice and Migrant Clinicians Network. Retrieved from https://www.farmworker justice.org/sites/default/files/documents/Heat20 Related20Illnesses.pdf

Samuel, H. D. (2000). Troubled passage: The labor movement and the Fair Labor Standards Act. Monthly Labor Review. Retrieved from http://www.bls.gov/opub/mlr/2000/12/ art3full.pdf

Stoecklin-Marois, M., Hennessy-Burt, T., Mitchell, D., \& Schenker, M. (2013). Heat-related illness knowledge and practices among California hired farm workers in the MICASA study. Industrial Health, 51(1), 4755. http://dx.doi.org/10.2486/indhealth.2012-0128

Theorell, T. (2003). Democracy at work and its relationship to health. In P. L. Perrewé \& D. C. Ganster (Eds.), Emotional and physiological processes and positive intervention strategies: Research in occupational stress and well-being (Vol. 3, pp. 323-357). Bingley, UK: Emerald Group Publishing. http://dx.doi.org/10.1016/S1479-3555(03)03008-7

Thomas, R. J. (1985). Citizenship, gender and work: Social organization of industrial agriculture. Berkeley: University of California Press.

U.S. Department of Labor, Occupational Safety and Health Administration [OSHA]. (n.d.-a). Heat fatalities [Map]. Retrieved from https://www.osha. gov/SLTC/heatillness/map text.html

U.S. Department of Labor, OSHA. (n.d.-b). Training requirements in OSHA standards. Retrieved from https://www.osha.gov/Publications/osha2254.pdf

U.S. Department of Labor, OSHA. (n.d.-c). Welcome to OSHA's campaign to prevent heat illness in outdoor workers. Retrieved from https://www. osha.gov/SLTC/heatillness/index.html

U.S. Department of Labor, Bureau of Labor Statistics. (n.d.). Occupational injuries/illnesses and fatal injuries profiles [Table]. Retrieved from http://data.bls.gov/gqt/InitialPage

Villarejo, D., \& Runsten, D. (1993). California's agricultural dilemma: Higher production and lower wages. Davis: California Institute for Rural Studies.

Walker, R. A. (2004). The conquest of bread: 150 years of agribusiness in California. New York: The New Press.

Wells, M. J. (1996). Strawberry fields: Politics, class, and work in California agriculture. Ithaca, New York: Cornell University Press.

Westerlund, H., Nyberg, A., Bernin, P., Hyde, M., Oxenstierna, G., Jäppinen, P.,...Theorell, T. (2010). Managerial leadership is associated with employee stress, health, and sickness absence independently of the demand-control-support model. Work, 37(1), 71-79. http://dx.doi.org/10.3233/WOR-2010$\underline{1058}$ 